\title{
Drug Information Resources at Private Community Pharmacies in Kuwait
}

\author{
Douglas E. Ball Fatma Al-Othman \\ Department of Pharmacy Practice, Faculty of Pharmacy, Kuwait University, Kuwait
}

\section{Key Words}

Drug information - Retail pharmacies - Pharmaceutical services

\begin{abstract}
Objective: To investigate the drug information resources available in private community pharmacies in Kuwait. Materials and Methods: Pharmacists at a sample of 20 private community (retail) pharmacies completed a self-administered questionnaire of available information resources and perceived appropriate information resources to answer five drug information questions. Results: All pharmacies had at least one reference book but they were outdated. The Middle East Medical Index was most commonly found and three pharmacies had internet access. Half of the respondents reported getting medicines information directly from the pharmaceutical companies, usually through pharmaceutical representatives. Most pharmacists could identify appropriate information resources for drug dosing and drug interactions but did not fare well for medicine identification and primary research evidence. Conclusion: The poor quality and outdated drug information resources in private community pharmacies will affect the quality of information provided to clients and prescribers and have an adverse effect on the role pharmacists can play in the health system in Kuwait.

Copyright $\odot 2007$ S. Karger AG, Basel
\end{abstract}

\section{Introduction}

The role of the community pharmacist has changed to one involving 'extended roles' such as educating, monitoring and caring for patients in collaboration with other health professionals [1]. Drug information is an integral part of these functions and also of continuing professional development [2]. Pharmacists therefore need access to comprehensive, reliable and up-to-date information on medicines, balancing primary (e.g. biomedical journals), secondary (e.g. Medline) and tertiary sources (e.g. reference books) [2]. In the absence of independent resources, pharmacists will have to rely on the information provided by pharmaceutical companies.

Kuwait has a comprehensive public health system. This is complemented by private facilities including over 200 community pharmacies (commonly called 'private pharmacies' within Kuwait). The role of the pharmacist as a health professional is not fully developed compared with some other nations. This survey investigated the drug information resources available in community pharmacies in Kuwait and pharmacists' abilities to identify those appropriate to specific situations.

\begin{tabular}{ll}
\hline KARGER & (c) 2007 S. Karger AG, Basel \\
Fax $+41613061234-7571 / 07 / 0162-0107 \$ 23.50 / 0$ \\
$\begin{array}{l}\text { E-Mail karger@karger.ch } \\
\text { www.karger.com }\end{array}$ & $\begin{array}{l}\text { Accessible online at: } \\
\text { www.karger.com/mpp }\end{array}$
\end{tabular}


Table 1. Pharmaceutical information resources identified at 20 community pharmacies in Kuwait

\begin{tabular}{lcllll}
\hline Information resource & \multicolumn{6}{c}{ Pharmacies with resource present, $\mathrm{n}$} \\
\cline { 2 - 6 } & $\begin{array}{l}\text { latest } \\
\text { edition }\end{array}$ & $\begin{array}{l}\text { previous } \\
\text { edition }\end{array}$ & $\begin{array}{l}\text { older } \\
\text { editions }\end{array}$ & $\begin{array}{l}\text { edition } \\
\text { not known }\end{array}$ & $\begin{array}{l}\text { total } \\
(\%)\end{array}$ \\
\hline Middle East Medical Index $^{1}$ & 0 & 3 & 17 & 0 & $20(100)$ \\
Kuwait Drug Index $^{2}$ & 19 & 0 & 0 & 0 & $19(95)$ \\
Martindale $^{3}$ & 0 & 0 & 10 & 3 & $13(65)$ \\
British National Formulary $^{4}$ & 0 & 0 & 2 & 1 & $3(15)$ \\
Kuwait National Formulary $^{5}$ & 0 & 2 & 1 & 0 & $3(15)$ \\
British Pharmacopoeia $^{6}$ & 0 & 0 & 1 & 1 & $2(10)$ \\
Drug Information Handbook $^{7}$ & 0 & 1 & 0 & 0 & $1(5)$ \\
\hline
\end{tabular}

${ }^{1}$ Abbreviated manufacturers' monographs; ${ }^{2}$ monographs of many registered medicines in Kuwait; ${ }^{3}$ comprehensive reference on medicines; ${ }^{4}$ British clinical guidance and abbreviated drug monographs; ${ }^{5}$ Ministry of Health extemporaneous compounding formulary; ${ }^{6}$ reference for extemporaneous compounding; ${ }^{7}$ American drug monographs and clinical information.

\section{Methods}

A self-administered questionnaire was designed to record information resources available in the pharmacy. A second section presented five mock medicines information enquiries and asked respondents to identify the most suitable information resource to be used from a list provided or to suggest a more appropriate choice. 'Correct' answers were determined based on the reliability, relevance and comprehensiveness of the resource to each case. The appropriateness of respondents' choice was determined by consensus of two evaluators. The scenarios were: dosing of a known drug in a rare condition (betahistine in Ménière's disease), drug interaction (warfarin and sulfinpyrazone), identification of a foreign medicine, uncommon adverse reaction (infertility with cyclophosphamide), and finding scientific evidence for a novel therapy (nevirapine to prevent mother-to-child transmission of HIV).

The questionnaire was distributed to a convenience sample of 20 community pharmacies from the Hawally and the Capital governorates during April 2004, equivalent to about $10 \%$ of community pharmacies in Kuwait. Consent to participate was provided by the pharmacist in charge after the purpose of the study was explained by an investigator.

\section{Results}

The pharmaceutical information resources identified are shown in table 1 . No electronic databases were present and only three pharmacies had internet access. Three pharmacies had general pharmacology texts (published in 1995, 2002, 2003), one had a general medical text (published in 2003) and one a medical dictionary. One pharmacist reported access to biomedical journals and $50 \%$ of respondents reported getting medicines information directly from the pharmaceutical companies, usually through pharmaceutical representatives.

In response to the five scenarios, no pharmacist correctly identified a suitable reference in all cases, three answered four cases correctly, seven answered three correctly, nine scored two marks and one pharmacist scored one out of five. Drug dosing resources were correctly identified by most respondents $(\mathrm{n}=16)$, interactions by 13 and side effects by 10; but few did well in medication identification $(n=2)$ or for finding evidence for a new therapy $(\mathrm{n}=1)$.

\section{Discussion}

This study found information resources in community pharmacies in Kuwait to be generally lacking and outdated. Although only a preliminary survey, the consistency of the results suggests this is a widespread problem.

Compounding extemporaneous preparations, e.g. making ointments, is not permitted in community pharmacies in Kuwait, with sales limited to finished products from pharmaceutical companies. It was therefore understandable that most pharmacies did not hold the Kuwait National Formulary or similar publications. Although Martindale was present in over half the pharmacies, the editions were generally very old (from the 1970s). The Kuwait Drug Index (latest edition in 1994/1996) and the Middle East Medicines Index were most commonly avail- 
able references. The Middle East Medicines Index is occasionally provided by pharmaceutical representatives but only contains limited information on selected products. It is thus of limited use and may have potentially misleading information, as has been found in a comparison of similar publications [3].

Less than a fifth of pharmacies had internet access to online drug information, which may be partly related to the lack of computerization of private pharmacies in $\mathrm{Ku}$ wait. The lack of internet and print resources could be a result of most pharmacies being run by expatriate employees rather than the owner. These pharmacists are likely to rely on the owner to provide information resources rather than supply their own. National legislation could require the latest edition of at least one comprehensive drug information text or computer database to be present at all private pharmacies. Existing regular pharmacy inspections by the Ministry of Health would permit this to be enforced.

The pharmacists' limited experience with suitable reference resources probably contributed to the poor re- sponses to the drug information scenarios. They performed well when drug company information would suffice, but were found wanting when more detailed information was required. Pharmaceutical company information is likely to be biased, with decreased emphasis on risks relative to benefits [4], and information from pharmaceutical representatives is often unreliable [5].

\section{Conclusions}

This study has shown that drug information resources in community pharmacies in Kuwait are often of poor quality and outdated. This will affect the quality of information provided to clients and prescribers. Further study is needed of the interaction between pharmaceutical companies and community pharmacists. Meanwhile, legal provisions requiring community pharmacies to have current copies of selected reference texts should be implemented without delay.

\section{References}

1 World Health Organization: The role of the pharmacist in the health care system. (WHO/ PHARM/94.569) Geneva, WHO, 1994.

2 Lee A: Medicines information; in Winfield AJ, Richards RME (eds): Pharmaceutical Practice, ed 3. Edinburgh, Churchill Livingstone, 2004.

3 Dikshit RK, Dikshit N: Commercial source of drug information: comparison between the United Kingdom and India. BMJ 1994; 309:990-991.
4 Keng A, Coley RM: Evaluating the accuracy of citations in drug promotional brochures. Ann Pharmacother 1994;28:1231-1235.

5 Ziegler MG, Lew P, Singer BC: The accuracy of drug information from pharmaceutical sales representatives. JAMA 1995;273:12961298. 